\title{
Ex situ conservation of Holstein-Friesian cattle: Comparing the Dutch, French, and US germplasm collections
}

\author{
C. Danchin-Burge,${ }^{*}+\ddagger^{1}$ S. J. Hiemstra, $\S$ and H. Blackburn\# \\ *AgroParisTech, UMR 1313 Génétique Animale et Biologie Intégrative, 75231 Paris 05, France \\ †INRA, UMR 1313 Génétique Animale et Biologie Intégrative, 78350 Jouy-en-Josas, France \\ †Institut de l'Elevage, 75595 Paris 12, France \\ $\S$ Centre for Genetic Resources, the Netherlands (CGN), Wageningen University and Research Centre, PO Box 65, 8200 AB Lelystad, \\ the Netherlands \\ \#National Animal Germplasm Program, National Center for Genetic Resources Preservation-Agricultural Research Service-USDA, \\ Ft. Collins, CO 80521
}

\section{ABSTRACT}

Holstein-Friesian (HF) gene bank collections were established in France, the Netherlands, and the United States to conserve genetic diversity for this breed. Genetic diversity of HF collections within and between countries was assessed and compared with active male HF populations in each country by using pedigree data. Measures of genetic diversity such as probability of gene origin inbreeding and kinship were calculated. The cryobanks have captured substantial amounts of genetic diversity for the HF compared with the current populations. A substantial part of the US, French, and Dutch collections seems to be genetically similar. On the other hand, the US collection in particular represents an interesting reservoir of HF genes of the past. Gene banks can play an important role in conserving genetic diversity within livestock breeds over time, and may support industry in the future when needed.

Key words: gene bank, genetic diversity, HolsteinFriesian

\section{INTRODUCTION}

Global action has been initiated to conserve animal genetic resources (FAO, 2007a). A country-driven response has been developed and includes the formation and operation of gene banks (FAO, 2007a). The establishment of gene banks using cryopreservation to secure the genetic diversity of livestock breeds has been assessed (Blackburn, 2004; FAO, 2007b). France, the Netherlands, and the United States were among the first countries to organize national cryobanks (Blackburn, 2004, 2009; Danchin-Burge et al., 2006; Woelders et al., 2006), which have been operational for more than $10 \mathrm{yr}$.

Received October 22, 2010

Accepted April 21, 2011.

${ }^{1}$ Corresponding author: coralie.danchin@inst-elevage.asso.fr
The contraction in Holstein-Friesian (HF) genetic diversity has been documented (Boichard et al., 1997; Sørensen et al., 2005; Mc Parland et al., 2007; Kim and Kirkpatrick, 2009) and as a result, all 3 countries have started HF collections. To better understand the diversity captured in HF gene bank collections, the genetic variability of germplasm collections was assessed within and between countries, and genetic variability of germplasm collections were compared with active male (AM) populations in each country. The objective of this study was to evaluate the HF collections developed by the 3 national gene banks and determine how well they have conserved genetic diversity of the respective HF populations over time.

\section{MATERIALS AND METHODS}

\section{Populations Studied and Data}

National HF germplasm collections were established at the beginning of the 1990s in the Netherlands (NLD), the United States (USA), and France (FRA). For the Dutch collection, managed by the Centre for Genetic Resources, the Netherlands, the majority of the $\mathrm{HF}$ bulls are from progeny testing programs operated by 2 commercial companies, Holland Genetics (Arnhem, the Netherlands) and Alta Genetics (Feerwerd, the Netherlands). The US collection consists of bulls sampled from the sire evaluation programs of 3 major AI companies: ABS Global (DeForest WI), Select Sires (Plain City, $\mathrm{OH}$ ), and Accelerated Genetics (Baraboo, WI), in addition to sample donations by the industry and university experimental populations. In France, the 2 primary selection objectives for a bull to enter into the cryobank have been (1) to preserve genetic gains and (2) to preserve selected and neutral genetic variability (Verrier et al., 2003). The bulls from all 3 national cryobanks will be referred as cryobank bulls $(\mathbf{C B N})$ in this article. The total number of $\mathrm{CBN}$ in the 3 countries was 8,892 (Table 1 ). 
Table 1. Number of cryobank bulls (CBN) and active males (AM), pedigree depth expressed as equivalent number of generations (EqG), number of top contributing ancestors accounting for $50 \%$ of the genes, and effective population size ( $\mathrm{Ne}$ ) for CBN and AM by country

\begin{tabular}{|c|c|c|c|c|c|c|c|c|}
\hline \multirow[b]{2}{*}{ Item } & \multicolumn{2}{|c|}{ Overall } & \multicolumn{2}{|c|}{ France } & \multicolumn{2}{|c|}{ The Netherlands } & \multicolumn{2}{|c|}{ United States } \\
\hline & $\mathrm{CBN}$ & AM & $\mathrm{CBN}$ & $\mathrm{AM}$ & $\mathrm{CBN}$ & $\mathrm{AM}$ & $\mathrm{CBN}$ & $\mathrm{AM}$ \\
\hline$E q G$ & 8.2 & 9.6 & 9.4 & 10.1 & 9.4 & 9.6 & 7.3 & 9.4 \\
\hline Total no. of founders & 10,302 & 8,568 & 1,990 & 4,702 & 5,532 & 3,921 & 7,948 & 5,562 \\
\hline Effective no. of founders & 1,234 & 113 & 100 & 105 & 115 & 115 & 784 & 115 \\
\hline Effective no. of ancestors & 84 & 17 & 14 & 15 & 17 & 17 & 77 & 17 \\
\hline $\mathrm{Ne}(\mathrm{SD})$ & $84(0.6)$ & $85(0.3)$ & $77(2.6)$ & $83(0.5)$ & $87(0.6)$ & $89(0.8)$ & $83(0.9)$ & $85(0.4)$ \\
\hline
\end{tabular}

To compare ex situ and in situ genetic variability, a population of active bulls in each country was sampled from the Interbull database (www.interbull.org) with the following criteria: each bull had to be born in the country where it was used; both parents of the bull were known; and birth years ranged from 2002 to 2006 (equivalent to 1 generation interval). In total, 12,932 active bulls were selected for this study (Table 1).

The pedigrees of the HF bulls stored in all $3 \mathrm{col}-$ lections (by January 2009) were provided by each country's breed association [Holstein Association USA (Brattleboro, VT) for the US collection, CRV (Arnhem, the Netherlands) for the Dutch collection, and INRACTIG (Jouy-en-Josas, France) for the French collection] and merged. For each animal, the file contained the animal's identification, sire and dam registration numbers, birth date, and sex. Including pedigreed ancestors, the file contained 92,256 individuals. All CBN bulls were classified by the decade in which they were born.

\section{Analysis of Genetic Variability}

Pedigrees were used to evaluate genetic variability of in situ and ex situ populations using the PEDIG software (Boichard, 2002, 2007). The principles, methods, and the corresponding equations are described in detail by Boichard et al. (1997); Baumung and Sölkner (2002), Leroy et al. (2006), and Danchin-Burge et al. (2010) have illustrated the software's use.

The equivalent generation number (EqG) was determined for each animal $(i)$ by

$$
E q G_{i}=\sum\left(\frac{1}{2}\right)^{n},
$$

with $n$ being the generation number of a given ancestor (e.g., 1 = parents, 2 = grandparents), and the sum being computed across all known ancestors of $i$. The $E q G$ for the whole collection (across the 3 countries) or within population was computed as the mean of $E q G_{i}$.

Ancestors without known parents were considered as noninbred and nonrelated founder animals. The effec- tive number of founders $\left(\mathbf{f}_{\mathrm{e}}\right)$ of a country's population was defined as the reciprocal of the probability $q_{j}$ (or expected contribution) that 2 genes drawn at random in the population originate from the same founder $j$ and was computed as

$$
f_{e}=1 / \sum_{k=1}^{f} q_{j}^{2} .
$$

The concept of a major ancestor, founder or not, as defined by Boichard et al. (1997) was used in the analysis. The major ancestors of the AM and CBN populations were detected, and their marginal expected contributions to the gene pool $\left(q_{k} ; \Sigma_{k} q_{k}=1\right.$, where $k$ is $k$ th ancestor) were computed using the method of Boichard et al. (1997). The effective number of ancestors $\left(\mathbf{f}_{\mathrm{a}}\right)$ was defined and computed in a similar way as the effective number of founders:

$$
f_{a}=1 / \sum_{k=1}^{f} q_{k}^{2} .
$$

The coefficient of inbreeding of each bull was computed using the method of Meuwissen and Luo (1992). The kinship coefficients (Malécot, 1948) among CBN from the different countries were computed, as were the kinship coefficient between $\mathrm{CBN}$ and $\mathrm{AM}$, and the kinship coefficient $\Phi$ for each CBN or AM bull with the rest of the male population.

Rate of inbreeding $(\boldsymbol{\Delta} \boldsymbol{F})$ was calculated by the method proposed by Gutiérrez et al. (2008, 2009). For each animal ( $i$ ) from the AM and CBN populations, the individual rate of inbreeding from its founders $\left(\Delta F_{i}\right)$ was computed as follows:

$$
\Delta F_{i}=1-\sqrt[E q G_{i}-1]{\left(1-F_{i}\right)},
$$

where $F_{i}$ is the coefficient of inbreeding of $i$ and $E q G_{i}$ is its individual EqG computed with equation [1]. The global rate of inbreeding $(\Delta F)$ was simply computed as the average of all individual rates of inbreeding $\left(\Delta F_{i}\right)$ of 
animals in the CBN and AM populations. The effective population size $(\mathrm{Ne})$ was computed according to the classical formula (Wright, 1969):

$$
N e=\frac{1}{2 \Delta F} .
$$

\section{Statistical Analyses}

Statistical analyses were performed to check if he EqG and $\Delta F$ could be used to set apart the populations and better characterize the collections. Each bull was categorized by country (FRA, NLD, or USA), category of population (AM or CBN), and birth period (4 class levels: 1979 and below, 1980-1989, 1990-1999, and 2000-2007), which defined a total of 12 sub-populations. An ANOVA was carried out for EqG with a model that included country, category of population within country, and birth period within category within country.

For $\Delta F, 66$ tests were run for simultaneous pairwise comparisons to check if the average $\Delta F$ was significantly different from one sub-population to another (as an example, the average $\Delta F$ of the AM French bulls born between 1990 and 1999 was tested versus the average $\Delta F$ of the CBN Dutch bulls born between 1980 and 1989). The initial $\alpha=0.05$ significance level was adjusted for simultaneous pairwise comparisons using the sequential Bonferroni correction approach.

Analyses were completed by using several procedures in SAS (v 9.1.3; SAS Inst. Inc., Cary NC). The PROC GLM procedure was used for the parametric statistics $(\mathrm{EqG})$. The procedure used for nonparametric statistics for categorical and nonnormal data $(\Delta F)$ was the Wilcoxon rank sum in PROC NPAR1WAY. The kinship coefficient matrix between and within the 12 different sub-populations (CBN by birth period and AM) was used to perform a cluster analysis and a principal component analysis (PCA).

To determine if distinct differences existed within and between the populations, the average method from the PROC CLUSTER routine in SAS was also used. The average method was selected because of its assumption that all individuals are members of the same group versus, for example, the Ward method, which assumes that all animals belong to their own cluster. The average kinship between one sub-population and another was used to compute the distance between the groups evaluated. The pseudo- $t$-test was used to determine the number of clusters present among the prespecified groups. The results from the cluster analysis were presented as a dendrogram, with each horizontal line representing 1 of the 12 sub-populations.
A PCA was also performed on the kinship coefficient matrix between and within the 12 sub-populations as an additional exercise to confirm the cluster analysis results. The PCA was performed by using the PROC PRINCOMP routine in SAS.

\section{RESULTS}

The number of bulls present in each collection and their pedigree size is described in Table 1. No bull was stored in more than one national collection, and no active bull was used in more than one country. The US and Dutch collections were larger than the French collection. Furthermore, the composition of the 3 cryobanks by birth year of the bulls was different. The majority of the Dutch bulls were born in the 1990s and 2000s, whereas approximately two-thirds of the US bulls were born in the 1980s and 1990s, the last third being divided between bulls born in the 1970s and after 2000. The French bulls were born in the 1990s through 2000s. The average birth year was 1989, 1998, and 2000 for the US, French, and Dutch collections, respectively.

\section{Pedigree Depth}

Pedigree depth was determined for all bulls by computing their traceable equivalent number of generations (Table 1). The EqG was identical for the French and the Dutch collections (9.4), but significantly lower $(P$ $<0.0001$ ) for the US collection (7.3). The lower EqG of the American collection is explainable by the birth year distribution of the bulls: on average, fewer ancestors were known for bulls born in the 1960s or the 1970s than for bulls born in the 1990s. The highest EqG was found for the French AM bulls (10.1) and differed significantly $(P<0.0001)$ from all other populations. We believe that these results are significantly different because the full pedigrees (including all ancestors) from the French AM bulls were added to the initial Interbull pedigree files, unlike the pedigrees of other AM bulls. All EqG were higher compared with other dairy cattle studies, where they ranged from 4 to $7 \mathrm{EqG}$ (Sørensen et al., 2005; Mc Parland et al., 2007).

\section{Probabilities of Gene Origin}

Among national collections (Table 1), the Dutch and French collections were similar in genetic variability. For example, the number of the top contributing ancestors accounting for $50 \%$ of the genes (N50) in a population was equal to 5 and 6 animals for the French and Dutch cryobanks, respectively, and these main ancestors were the same for both countries. The genetic variability 
represented in the US collection was higher $(\mathrm{N} 50=53)$ compared with the other gene banks. Although the ex situ N50 were variable, the AM N50 were, in essence, equal at 6, 7, and 6 for the French, Dutch and US populations, respectively. These numbers are low compared with the N50 from the US CBN, suggesting that the US collection contains more diversity than the in situ (AM) populations.

Values of $\mathrm{f}_{\mathrm{e}}$ and $\mathrm{f}_{\mathrm{a}}$ (Figure 1 ) decreased by 5 and $53 \%$, respectively, between the oldest bulls (born before 1970) and the bulls born in the 1970s, and by 18 and $69 \%$ compared with bulls born in the 2000s. Because most old bulls belonged to the US collection, these animals most likely contributed to the higher genetic variability of the US collection compared with both the $\mathrm{AM}$ and ex situ $(\mathrm{CBN})$ populations.

Table 2 lists the 5 main ancestors, by marginal contribution, for each CBN. Three of the 5 top bulls for the French and Dutch collections are the same, and neither country shares top 5 sires with the US collection. However, all $3 \mathrm{CBN}$ had a high degree of genetic relationship for the top 5 ancestors. For example, Elevation and Bell have Ivanhoe as a grandsire, whereas Chief is Mark's sire and Chief and Elevation are Blackstar's great grandsires.

Number of founders, $f_{e}$, and $f_{a}$ calculated by period for all CBN bulls are shown in Table 3. A substantial loss of genetic variability occurred between the 1970s and the 1990s. This result suggested that a bottleneck in the HF population was created in the 1970s with the massive use of Elevation and Chief, followed by Bell in the 1980s, as shown by their marginal contributions to the ex situ populations (Table 3). It appears that by 2000 the downward trend in genetic diversity had

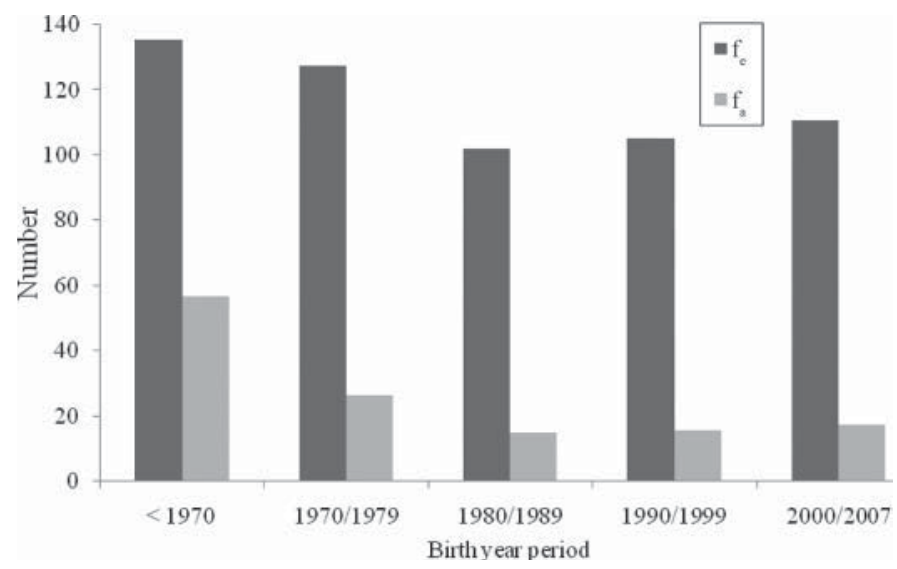

Figure 1. Change in the effective number of founders $\left(f_{e}\right)$ and effective number of ancestors $\left(f_{a}\right)$ by birth period of the cryobank bulls (all collections).

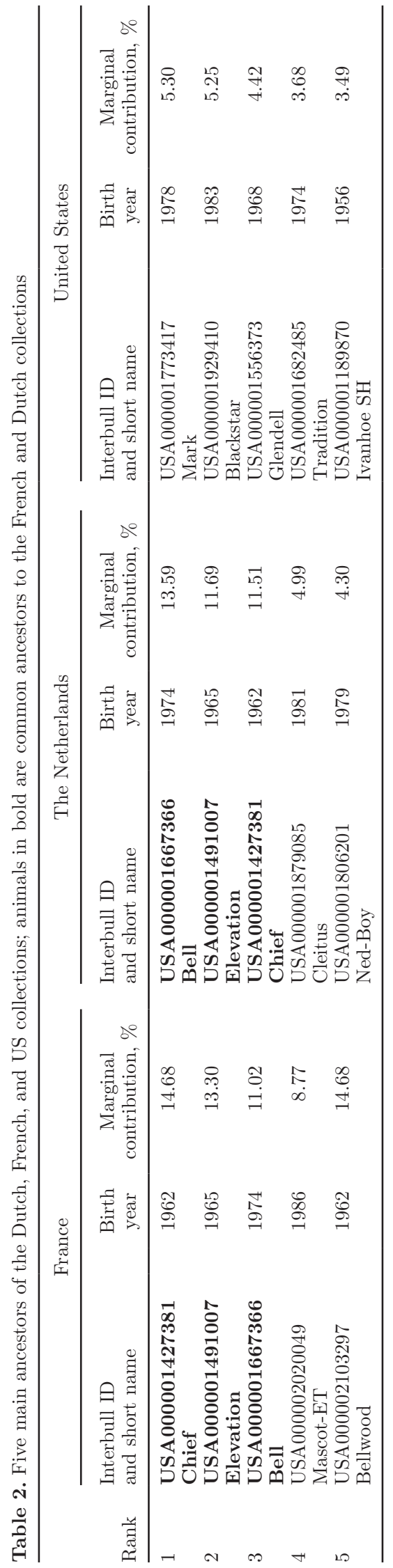

Journal of Dairy Science Vol. 94 No. 8, 2011 
Table 3. Changes in genetic variability criteria by decade for bulls' birth from all 3 collections

\begin{tabular}{lrccccc}
\hline Decade & $\begin{array}{c}\text { No. of } \\
\text { bulls }\end{array}$ & $\begin{array}{c}\text { Total no. of } \\
\text { founders }\end{array}$ & $\begin{array}{c}\text { No. of } \\
\text { effective } \\
\text { founders }\end{array}$ & $\begin{array}{c}\text { No. of } \\
\text { effective } \\
\text { ancestors }\end{array}$ & $\begin{array}{c}\text { Contribution } \\
\text { of the main } \\
\text { ancestor, \% }\end{array}$ & $\begin{array}{c}\text { No. of ancestors } \\
\text { Three main ancestors } \\
\text { of the genes }\end{array}$ \\
\hline$<1970$ & 78 & 354 & 135.5 & 56.8 & 7.0 & Kol, Ivanhoe, Abc Reflec \\
$1970-1979$ & 409 & 1,941 & 127.3 & 26.4 & 11.7 & Chief, Elevation, Ivanhoe \\
$1980-1989$ & 1,990 & 5,074 & 101.9 & 14.7 & 17.8 & Chief, Elevation, Bell \\
$1990-1999$ & 3,570 & 6,225 & 105.1 & 15.6 & 14.8 & Chief, Elevation, Bell \\
$2000-2007$ & 2,849 & 6,068 & 110.6 & 17.1 & 12.8 & Elevation, Chief, Bell \\
\hline
\end{tabular}

been stabilized, potentially in part due to the industry's awareness of inbreeding and implementation of procedures to minimize inbreeding in sire evaluation programs (Meuwissen, 1997; Colleau et al., 2009).

\section{Inbreeding}

As expected with all closed populations, the percentage of inbred animals was high $(>95 \%)$ for HF, and bulls' inbreeding in all the collections mirrors the level of the in situ populations (Table 4). Among cryobanks, the US collection had the highest percentage of highly inbred animals (20.1\%), with an average inbreeding level that exceeded $6.25 \%$. In that collection, very highly inbred animals, such as Aggravation Cavalier Image-Red (26.1\%), and Betsey Golden-Genes BoleroET $(25.2 \%)$, were found to be present.

Table 5 illustrates how $\mathrm{Ne}$ decreased substantially between the 1970s and 1980s. For the US and Dutch collections, $N e$ was reduced from 242 (1970s) to 71 (1990s) and from 127 (1980s) to 83 (1990s), respectively. Selection intensity became much higher during this period, with the establishment of selection programs that used BLUP and led to more related animals being selected as sires and dams. However, our $\mathrm{Ne}$ estimates are higher than what is usually found in the literature (e.g., 49 for Sørensen et al., 2005). We believe these results are due to the formula of $\Delta F$ used for calculations in the present study, which takes into consideration pedigree depth, whereas the classic calculation for inbreeding rate formula was applied in other studies.

\section{Average Kinship Within and Between Populations}

Average kinship within each population (Table 6) shows that the French collection had the most and the US collection the least closely related bulls. Fifty bulls represented in the US collection are from a randomly mated population developed by the University of Minnesota (Starkenburg et al., 1997), which contributes to the lower average kinship of the collection. The French collection was slightly more related to the Dutch than to the American collection. French bulls were as related to the Dutch collection as Dutch bulls were among themselves.

The average kinship of the least related French CBN bulls with the AM animals was $>4 \%$. This value is superior to the kinship value between 2 animals that have a great-grandparent in common $(3.125 \%)$. The highest kinship values in all collections were between bulls that had, on average, a common grandparent within the respective AM. However, some Dutch and US CBN bulls were completely unrelated from the AM. Apart from the bulls from the University of Minnesota, some US bulls came from lineages that are extinct from the pedigrees of the current population. The Dutch collection holds HF bulls with original Dutch Friesian genes, thereby expanding the genetic diversity of their collection.

The country of origin of the sires of the bulls in cryobanks varied by country: 91,59 , and $35 \%$ (USA, NLD, and FRA, respectively) of the CBN bull sires were born in the country in which the cryobank was maintained.

Table 4. Inbreeding $(F)$ in the cryobank $(\mathrm{CBN})$ and active $(\mathrm{AM})$ bull populations

\begin{tabular}{|c|c|c|c|c|}
\hline Population & $\begin{array}{c}\text { Average rate } \\
\text { of inbreeding, }{ }^{1} \%\end{array}$ & $\begin{array}{l}\text { Proportion (\%) } \\
\text { of inbred animals }\end{array}$ & $\begin{array}{l}\text { Proportion (\%) } \\
\text { of animals } \\
\text { with } F>6.25 \%\end{array}$ & $\underset{\%}{\operatorname{Maximum}} F$, \\
\hline French CBN & 0.65 & 100 & 19.4 & 16.3 \\
\hline The Netherlands CBN & 0.58 & 99.6 & 18.7 & 15.0 \\
\hline The Netherlands AM & 0.56 & 96.7 & 19.0 & 26.9 \\
\hline US CBN & 0.60 & 95.1 & 20.1 & 26.1 \\
\hline
\end{tabular}

${ }^{1}$ Following the definition stated in equation [4]. 
Table 5. Change of the effective population size $N e(\mathrm{SD})$ by decade and collection

\begin{tabular}{lccc}
\hline Birth decade & France & The Netherlands & United States \\
\hline$<1970$ & & & $107(29.4)$ \\
$1970-1979$ & & $127(63.3)$ & $242(24.0)$ \\
$1980-1989$ & $78(3.6)$ & $83(1.2)$ & $90(2.1)$ \\
$1990-1999$ & $75(3.1)$ & $88(0.7)$ & $72(0.8)$ \\
$2000-2007$ & &
\end{tabular}

The low percentage of bulls sires born in France reflects the fact that French breeders actively sought bulls from other Europe countries and North America for use in their production system. In general, these percentages indicate a vibrant international exchange of genetic resources conducted by the private sector.

\section{Statistical Analyses}

The model effects for the variance analyses on $\mathrm{EqG}$, ranked from largest to smallest, were category of population (within a country), country, and birth period (within category within country). All effects were significant $(P<0.0001)$ with a model $\mathrm{r}^{2}$ equal to $59 \%$. Levels of significance within the category of population effect were described when presented with pedigree depth results.

Among the 66 statistical tests realized to compare the average $\Delta F$ values between sub-populations, 15 were found not significant after sequential Bonferroni correction. Significance of the results and average $\Delta F$ value per category are presented in Table 7 . The 1980s sub-population of US CBN bulls was found to be statistically different $(P<0.05)$ from all the other sub-populations. On the other hand, 7 out of the 11 tests realized for the FRA CBN bulls from the 1990s sub-population were found not different $(P>0.05)$ from those of the other sub-populations.

To further elaborate on the uniqueness of the in situ and ex situ (including the subdivisions by decade) populations, cluster analysis was performed assuming 12 sub-populations defined by country, type of bulls (CBN or AM), and period of bull birth (Figure 2).
Significance of the pseudo- $t$-test was found with 6 clusters. Figure 2 suggests that older bulls that are members of the US and Dutch CBN collections (USA CBN bulls from the 1970s and Dutch CBN bulls from the 1980s) are genetically distinct from the other 4 groups. Otherwise, the populations tended to be clustered by country. The Dutch groups (AM and CBN bulls from the 1990s and CBN bulls from the 2000s) formed a single cluster, suggesting that the Dutch $\mathrm{CBN}$ has captured existing levels of genetic diversity in the AM population. The USA CBN bulls from the 1980s joined with the Dutch groups, perhaps indicating a point in time when closer associations between the countries HF existed. The FRA CBN bulls from the 2000s sub-population were found to be distinct due to the addition of French bulls that were not typically used in the commercial dairy sector. The remaining 5 subpopulations were placed in the same cluster, suggesting that the USA CBN bulls from the 2000s, the USA CBN bulls from the 1990s, the FRA CBN bulls from the 1990s, the AM FRA, and AM USA were genetically similar, and therefore the CBN for both countries have sufficiently sampled the AM populations.

The PCA results supported results from the cluster analysis. The PCA first component explained $88 \%$ of the variation. On the first PCA axis, the older bulls in the US and Dutch collections (USA CBN bulls from the 1970s and NLD CBN bulls from the 1980s) were distinct from each other and the other sub-populations. Otherwise, the populations tended to be grouped by country. The PCA second and third components explained minor levels of variation (6 and $3 \%$, respectively). Because the analysis was performed on an individual breed, these components would be expected to be numerically small.

\section{DISCUSSION}

Our primary question was to determine how well the gene banks have captured the genetic diversity of the HF breed. Based upon $f_{e}, f_{a}$, and the similarity of major bulls in the active bull list and collections, the data sug-

Table 6. Within- (diagonal) and between-population average kinship (\%) for the active males (AM) and cryobank bulls $(\mathrm{CBN})$ by country ${ }^{1}$

\begin{tabular}{lcccccc}
\hline & AM FRA & AM NLD & AM USA & CBN FRA & CBN NLD & CBN USA \\
\hline AM FRA & 6.25 & & & & & \\
AM NLD & 5.27 & 5.27 & & & & \\
AM USA & 5.55 & 4.81 & 5.72 & & & \\
CBN FRA & 6.00 & 5.15 & 5.13 & 6.77 & & \\
CBN NLD & 4.98 & 5.02 & 4.41 & 5.16 & 5.14 & 4.87 \\
CBN USA & 4.94 & 4.38 & 4.77 & 5.00 & 4.26 & 4 \\
\hline
\end{tabular}

${ }^{1} \mathrm{FRA}=$ France; NLD $=$ the Netherlands, USA = United States. 


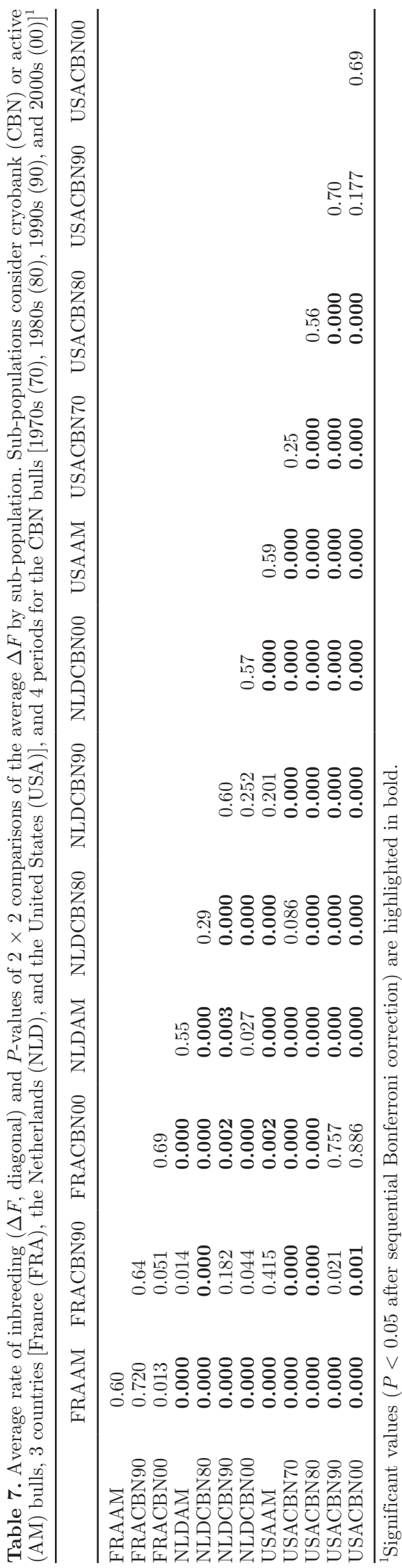

gest that the 3 gene bank acquisitions are equivalent to the AM in genetic diversity. Within the United States, the germplasm collected has a greater level of genetic variation than the current active population. This is further supported by the determination that the collection contains samples from bulls whose lineages are not present in the current population. For the Netherlands, the genetic variability of the active population and the collections seemed to mirror each other (Figure 2). In addition, the recent Dutch male populations (born after 1990) were slightly less related between themselves and the other populations in the study (Figure 2). The French collection was slightly less variable than the active population, probably due to the collection's small size compared with the AM population.

The global connectedness of HF genetics was also reflected in the results. The present analysis (results not shown) showed that 3 main ancestors (Chief, Elevation, and Bell) of the AM, based on their marginal expected contributions, were the same in all 3 AM populations. The importance of these bulls to the breed is also reflected in the collections, because they were found to be major ancestors in all 3 collections. The use of only bulls in this study may have introduced some bias, but within the dairy breeding industry, the genetic relationships among bulls are the principal driver of genetic diversity due to the substantial use of AI.

The current collections contain samples that span more than 50 yr of genetic change based upon bull year of birth. As a result, they offer the industry and research communities a resource for future experimentation and the introduction of genetic variability that may become lost. Collection utilization has already occurred within the US collection, where more than 700 animals have been used in a variety of genomic studies (McGinnis et al., 2010). To further expand a country's respective collection, the following activities are suggested. In France, additional collection efforts are needed to effectively capture the genetic variability of the current in situ population. In France (and the Netherlands), the proportion of non-AI bulls is close to zero; this percentage is higher in the United States. Further investigation via the approach described by Blackburn (2009) is needed to include non-AI bulls present in the United States in situ population. Such a study would determine whether these herds have genetic variability not represented in the US cryobank; if this is the case, they could be potential candidates for germplasm donation.

An interesting question this study raises is whether the 3 gene banks should be considered independent when further developing their HF collections. Specifically, because overlap exists in the collections, should efforts be made to reduce the redundancy? Our posi- 


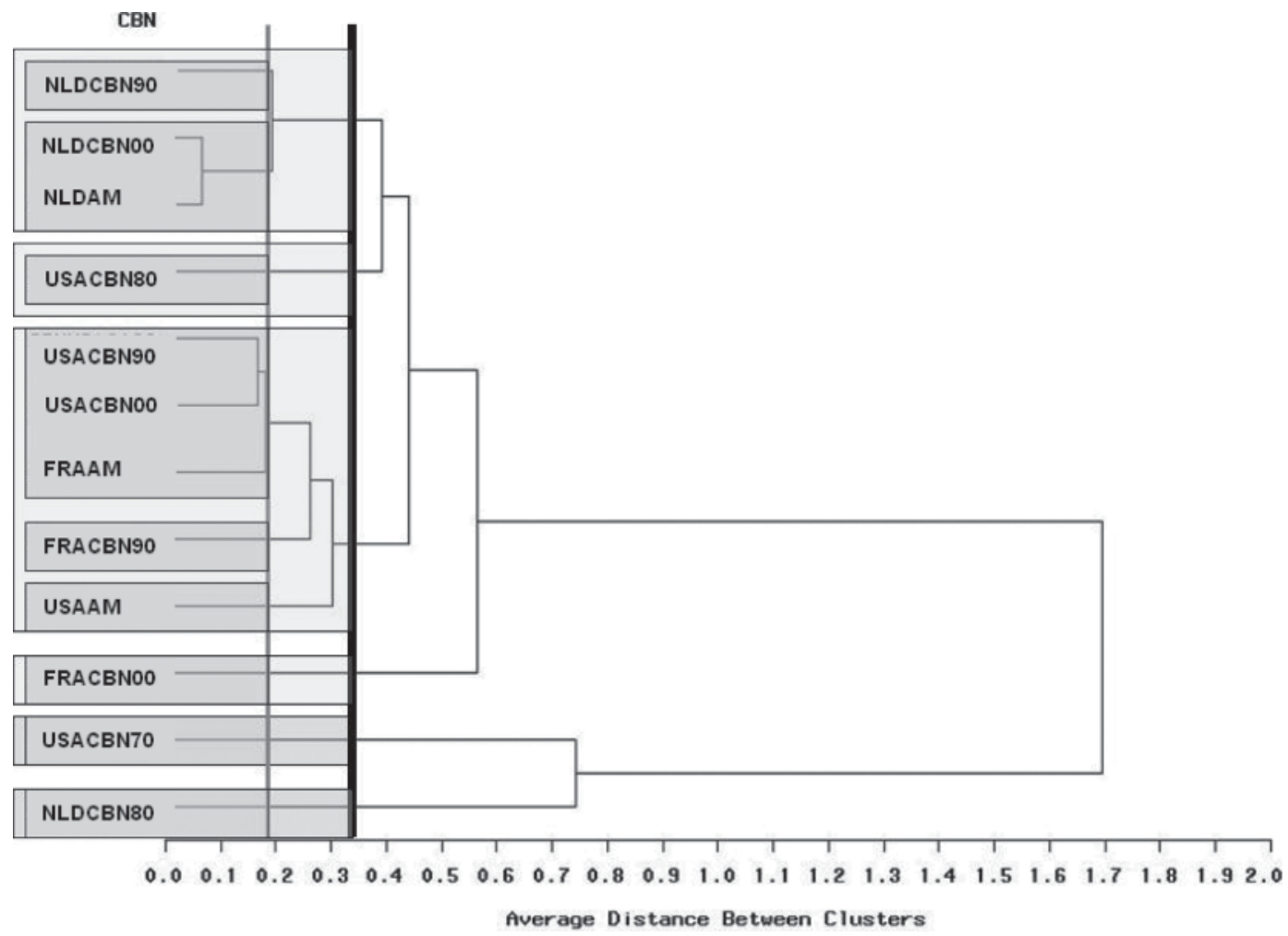

Figure 2. Average kinship between the 12 populations shown in a 2-dimensional scaling plot calculated from the kinship matrix: sub-populations consider cryobank (CBN) or active (AM) bulls, 3 countries [France (FRA), the Netherlands (NLD), and the United States (USA)], and 4 periods for the CBN bulls [1970s (70), 1980s (80), 1990s (90), and 2000s (00)].

tion would be that each gene bank becomes aware, to the appropriate level based upon industry and governmental interest, of each other's collection status and efforts. However, the collections should be viewed as independent entities and any redundancy for such a globally important breed brings international benefits. Furthermore, such an approach addresses several issues. From a policy perspective, it fulfills each nation's commitment to managing its own genetic resources, as agreed upon in the Interlaken Declaration (FAO, 2007a). From a practical standpoint, the germplasm is more readily available for within-country use, which eliminates the need to acquire importing and exporting permits, and minimizes the need for any further types of agreement in monitoring the exchange of genetic resources between countries. Moreover, costs of acquiring or transfer semen of AI bulls to national gene bank collections are relatively low.

\section{CONCLUSIONS}

Data used in the present study suggest that the 3 national cryobanks have captured substantial amounts of genetic diversity for the HF breed compared with the current active bull population. A significant por- tion of the US, French, and Dutch collections appear to be genetically similar. The US collection represents an interesting reservoir of $\mathrm{HF}$ genetics from the past. The Dutch collection preserves animals that are representative of the ancestor of the HF (i.e., the Dutch Friesian), illustrating how gene banks can support the conservation of genetic diversity and serve as a DNA resource for research purposes. Although the French collection is small, it seems to capture current genetic variation as much as the other populations. A corollary from this cryobank comparison study is that it emphasized again that the genetic variability of the HF breed is relatively low and similar in different countries. As a result, countries with substantial HF populations may wish to acquire germplasm samples from older bulls that may exist in AI centers and that may be less related to the total population, and store them in their national gene bank. More specifically, special efforts could be made to find founders and, in Europe, to place emphasis on conservation of breeds that were developed before the HF populations, such as the Dutch Friesian, a founder breed of the HF. We suggest further exploration of the genetic diversity of $\mathrm{HF}$ at the molecular level. As these results are obtained, new insights (e.g., differences in allele frequencies) will become more apparent and enable 
gene banks to make additional assessments concerning collection development and maintenance of the genetic diversity within the HF populations.

\section{ACKNOWLEDGMENTS}

We are grateful to the editor and two anonymous referees for helpful comments on the manuscript, and Grégoire Leroy (UMR 1313 INRA/AgroParisTech) for his help in designing the nonparametric statistics.

\section{REFERENCES}

Baumung, R., and J. Sölkner. 2002. Analysis of pedigrees of TuxZillertal, Carinthian Blond and Original Pinzgau cattle population in Austria. J. Anim. Breed. Genet. 119:175-181.

Blackburn, H. 2009. Genebank development for the conservation of livestock genetic resources in the United States of America. Livest. Sci. 120:196-203.

Blackburn, H. D. 2004. Development of national animal genetic resource programs. Reprod. Fertil. Dev. 16:27-32.

Boichard, D. 2002. PEDIG: A Fortran package for pedigree analysis suited for large populations. Commun. 28-13 in Proc. 7th World Congr. Genet. Appl. Livest. Prod., Montpellier, France. INRA, Montpellier, France.

Boichard, D. 2007. http://dga.jouy.inra.fr/sgqa/article.php3?id_ article $=110$.

Boichard, D., L. Maignel, and E. Verrier. 1997. The value of using probabilities of gene origin to measure genetic variability in a population. Genet. Sel. Evol. 29:5-23.

Colleau, J. J., K. Tual, H. de Preaumont, and D. Regaldo. 2009 A mating method accounting for inbreeding and multi-trait selection in dairy cattle populations. Genet. Sel. Evol. 41:7. doi:10.1186/1297-9686-41-7.

Danchin-Burge, C., I. Palhière, D. François, B. Bibé, G. Leroy, and E. Verrier. 2010. Pedigree analysis of seven small French sheep populations and implications for the management of rare breeds. J. Anim. Sci. 88:505-516.

Danchin-Burge, C., E. Verrier, S. Moureaux, and M. Tixier-Boichard. 2006. Sampling protocols and review of the French National Cryobank collections. Commun. 33-3 in Proc. 8th World Congr. Genet. Appl. Livest. Prod., Belo Horizonte MG, Brazil. EMBRAPA, Belo Horizonte, Brazil.
FAO. 2007a. Global Plan of Action for Animal Genetic Resources and the Interlaken Declaration. FAO, Rome, Italy.

FAO. 2007b. The State of the World's Animal Genetic Resources for Food and Agriculture. FAO, Rome, Italy.

Gutiérrez, J. P., I. Cervantes, and F. Goyache. 2009. Improving the estimation of realized effective population sizes in farm animals. J. Anim. Breed. Genet. 126:327-332.

Gutiérrez, J. P., I. Cervantes, A. Molina, M. Valera, and F. Goyache. 2008. Individual increase in inbreeding allows estimating effective sizes from pedigrees. Genet. Sel. Evol. 40:359-378.

Kim. E. S., and B. W. Kirkpatrick. 2009. Linkage disequilibrium in the North American Holstein population. Anim. Genet. 40:279-288.

Leroy, G., X. Rognon, A. Varlet, C. Joffrin, and E. Verrier. 2006. Genetic variability in French dog breeds assessed by pedigree data. J. Anim. Breed. Genet. 123:1-9.

Malécot, G. 1948. Les Mathématiques de L'Hérédité. Masson, Paris, France.

Mc Ginnis, L, S. Durham, and A. Perry. 2010. Animal gene collections support U.S. research. Agric. Res. 58:12-14.

Mc Parland, S., J. F. Kearney, M. Rath, and D. P. Berry. 2007. Inbreeding trends and pedigree analysis of Irish dairy and beef cattle populations. J. Anim. Sci. 85:322-331.

Meuwissen, T. H. E. 1997. Maximizing the response to selection with a predefined rate of inbreeding. J. Anim. Sci. 75:934-940.

Meuwissen, T. H. E., and Z. Luo. 1992. Computing inbreeding coefficient in large populations. Genet. Sel. Evol. 24:305-313.

Sørensen, A. C., M. K. Sørensen, and P. Berg. 2005. Inbreeding in Danish dairy cattle breeds. J. Dairy Sci. 88:1865-1872.

Starkenburg, R. J., L. B. Hansen, M. E. Kehrli Jr., and H. ChesterJones. 1997. Frequencies and effects of alternative DRB3.2 alleles of bovine lymphocyte antigen for Holsteins in milk selection and control lines. J. Dairy Sci. 80:3411-3419.

Verrier, E., C. Danchin-Burge, S. Moureaux, L. Ollivier, M. TixierBoichard, M. J. Maignel, J. P. Bidanel, and F. Clement. 2003. What should be preserved: Genetic goals and collection protocols for the French National Cryobank. Pages 79-89 in Workshop on Cryopreservation of AnGR in Europe, Paris, France. D. Planchenaults, Paris, France.

Woelders, H., C. A. Zuidberg, and S. J. Hiemstra. 2006. Animal genetic resources conservation in the Netherlands and Europe: Poultry perspective. Poult. Sci. 85:216-222.

Wright, S. 1969. Evolution and the Genetics of Populations: The Theory of Gene Frequencies, Vol. 2. University of Chicago Press, Chicago, IL. 